\title{
Risk Stratification at Patients with the Defect Vessels and High Blood Pressure: New Mathematical Model
}

\author{
Nagay AV*, Khamidullaeva GA and Kurbanov RD \\ Department of Arterial Hypertension and Molecular Genetics Research Republican Specialized Scientific-practical medical Center of \\ Cardiology, Tashkent, Uzbekistan
}

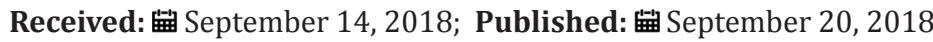

*Corresponding author: Aleksandr Nagay, Department of Arterial Hypertension and Molecular Genetics Research Republican Specialized Scientific- practical medical Center of Cardiology 4, Osiyo Str Mirzo-Ulugbek 100052, Tashkent Uzbekistan

\section{Research Article}

It is noted, that today the population of Uzbekistan unprecedentedly increases consumption of salt and have low physical activity in general. Besides for the last 25 years, the population of Uzbekistan was enlarged twice. Today such tendency of population increase is followed by its aging. The positive aspect of this phenomenon is augmentation of average life expectancy. However, a negative side that the augmentation of life expectancy doesn't correspond to its quality. Deterioration first of all is bound to augmentation of prevalence of age chronic diseases, such as a hypertension. For example, today in Uzbekistan, one of three adults has raised by the $\mathrm{ABP}$, and excess weight occurs at every second (WHO/STEPS 2014). As a result it caused double increasing of visits of the doctor and total number of patients in general. The purpose of our research was in developing the prognostic model of the turnpike arteries biological age at hypertensive patients. To study the arterial blood pressure daily profile at sick with the arterial hypertension (AH) with the metabolic syndrome (MS) [1].

\section{Material and Methods}

The study included 96 healthy volunteers and 96 men with arterial hypertension AH in average age of $56.06 \pm 7.86$ years, diagnosed abdominal obesity (BMI $34.54 \pm 3.83 \mathrm{~kg} / \mathrm{m}^{2}$ ) and metabolic disorders. In order to estimate the clinical status, the following risk factors were studied: elevated arterial BP, smoking; clinical and biochemical parameters: 12-lead ECG; 24-hour Holter ECG monitoring; exercise stress test; echocardiography (EchoCG); carotid artery intima-media thickness (IMT) [2,3].

\section{Prognostic Model}

We selected clinical signs for creation of the prognostic table by means of the method of the consecutive diagnostic procedure based on a technique of the sequential analysis offered by A. Wald. For each informative sign gradation of this or that indicator were selected to equal the diagnostic value of each of indicators (Figure 1). On the basis of local research grant analysis the calculator of risk was developed to provide patients with AH I-II -degrees the important prognostic information. We also considered that population of modern Uzbekistan have tendencies of negative impact at vessels damage such as: salt and the increased body weight. As a result, nine best factors for stratification of risk at patients with the defect vessels and raised SBP, including easy available, clinical parameters were included in this calculator (Figure 1). We applied multistage stratification of risk, based on nine parameters which were included in the developed equation of nine factors [4]:

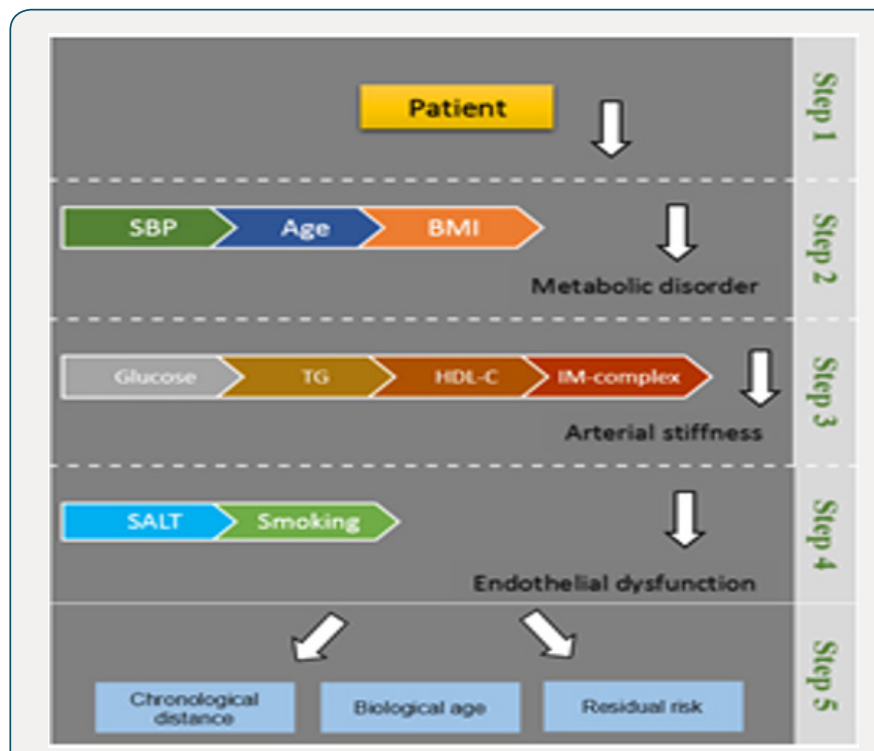

Figure 1: Prognostic model.

(a-SBP; b- IMT intima-media thickness; s- Salt; d-smoking; e-age; *m- metabolic index ${ }^{*} \mathrm{~m}=\mathrm{t} \times \mathrm{g} / \mathrm{h} 2$; i-BMI; $\mathrm{t}$ Triglycerides, g- Glucose; h- HDL-C). 


$$
\frac{(a+b+s+d) x e}{100}: 2+(* m+i-18)
$$

During this experiment, patients noted informational content of the calculator for the objective comprehension of their cardiovascular status (Sensitivity-85\%, Specificity-63\%) (Table 1). However long-term preventive effect, in prevention of the recurrence was not confirmed [5-7].

Table 1: Example Clinical data.

\begin{tabular}{|c|c|c|}
\hline Parameters & Patient & Healthy \\
\hline SBP mm & 155 & 120 \\
\hline Age & 50 & 50 \\
\hline BMI & 28 & 27 \\
\hline Glucose (mmol/l) & 6 & 5,6 \\
\hline Triglycerides (mg/dl) & 160 & 150 \\
\hline HDL-C (mg/dl) & 40 & 40 \\
\hline IMT & 0,9 & 0,9 \\
\hline Salt NaCl/24 & 15 & 18 \\
\hline Smoking & 18 & 50 years \\
\hline Biological age of vessels & 62 years & 4.4 \\
\hline Metabolic index & 5.1 & \\
\hline
\end{tabular}

$$
\mathrm{m}=\frac{\text { Triglycerides }(\mathrm{mmo} / \Omega) \times \text { Glucose }(\mathrm{mmo} / \Omega)}{\mathrm{HDL}-\mathrm{C} \mathrm{mmo//}{ }^{2}}=\frac{1.8 \times 6}{1.05 \times 2}=5.1
$$

$\mathrm{HDL}-\mathrm{C} \mathrm{mmol} / \mathrm{l}=\frac{\mathrm{HDL}-\mathrm{C}(\mathrm{mg} / \mathrm{d}))}{37.8}=\frac{40}{37.8}=1.05 \mathrm{mmol} /$

Triglycerides $(\mathrm{mmo} / \mathrm{h})=\frac{\text { Triglycerides } \mathrm{mg} / \mathrm{dl}}{88.6}=\frac{160}{88.6}=1.8 \mathrm{mmol} /$

$$
\begin{aligned}
& \frac{(S B P+\text { IMcomplex }+ \text { saltNaCl } / 24+\text { smoking }) * \text { Age }}{100}: 2+(m+B M I-18) \\
& \frac{(155+0.9+15+18) * 50}{100}: 2+(5.1+28-18)=62
\end{aligned}
$$

\section{Conclusion}

On completion of the therapy clinical tests indicated the high sensitivity at average specificity model that was acceptable in an opportunity to estimate medical effect. Unfortunately, the calculator could show the rate of damage vessels in the cases of actual disease, but not in cases of its prediction or probable emergence.

\section{References}

1. Asmar RG (1999) Reversion of arterial abnormalities by long-term antihypertensive therapy in a large population. The Complior study. J Hypertens p. 3-9.

2. Guarmi P, Tedeschi C, Giordano G, Messina V, Cicatiello A, et al. (1994) Effects of hypertension on intiml-medial thickness, left ventricular mass and aortic distensibility. Int Angiol 13(4): 317-22.

3. Kotchen T, Cowley A Jr, Frohlich E (2013) Salt in health and disease a delicate balance. N Engl J Med 368(26): 2531-2532.

4. Kupari M, Hekali P, Keto P, Poutanen VP, Matti J, et al. (1994) Relation of aortic stiffness to factors modifying the risk of atherosclerosis in healthy people. Arterioscler Thromb 14: 386-394.

5. Nichols, Wilmer W (1998) McDonald blood flow in arteries: Theoretical, experimental and clinical principles, ( $4^{\text {th }}$ edn). London Arnold 477-552.

6. Oparil S (2014) Low sodium intake--cardiovascular health benefit or risk?. N Engl J Med 371(7): 677-679.
This work is licensed under Creative Commons Attribution 4.0 License

To Submit Your Article Click Here: Submit Article

DOI: 10.32474/OAJCAM.2018.01.000101

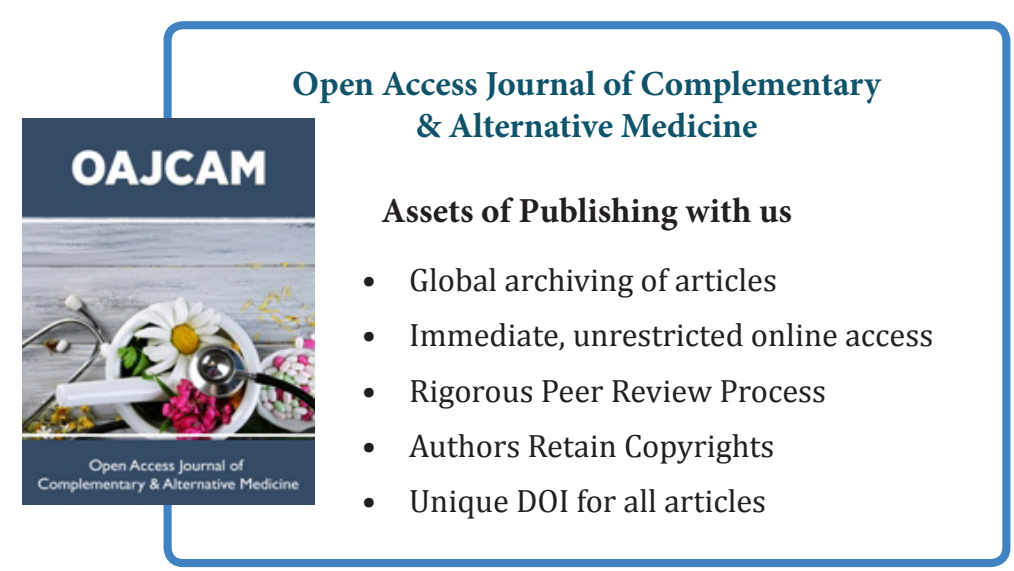

